
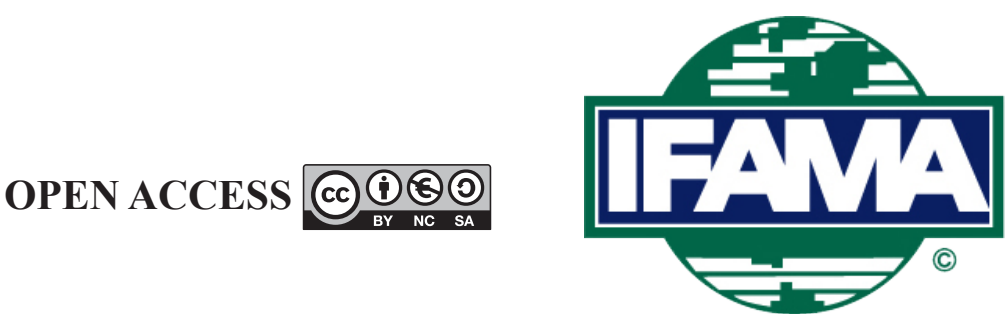

You Tuhe Click here to view

You Tube authors' intro video

International Food and Agribusiness Management Review

Volume 20 Issue 5, 2017; DOI: 10.22434/IFAMR2017.0074

Received: 27 July 2017 / Accepted: 18 August 2017

\title{
When Amazon ate Whole Foods: big changes for Big Food INDUSTRY SPEAKS
}

\author{
Kate Phillips-Connolly ${ }^{\mathrm{a}}$ and Aidan J. Connolly ${ }^{\circledR b}$ \\ ${ }^{a}$ Lecturer, Trinity College, University of Dublin, College Green, Dublin 2, Ireland; \\ Director, Abhaile Consulting, 271 Beach Road N, Wilmington, NC 28403, USA \\ ${ }^{b}$ Chief Innovation Officer and Vice President, Corporate Accounts, Alltech, \\ 3031 Catnip Hill Road, Nicholasville, KY 40356, USA; \\ Associate Professor of Marketing, University College, Dublin, Ireland; \\ Adjunct Agribusiness Professor, China Agricultural University, Beijing, China P.R.
}

\begin{abstract}
The grocery store is ground zero in the tsunami of change facing Big Food. Consumers are changing how they relate to grocery stores, increasingly circling the perimeter, focusing on produce and preferentially choosing fresh, local, and new, even unknown, brands while spending less time in the processed food aisles in the center. The next generation, the millenials, are increasingly shunning traditional outlets when buying food. Traditional leading brands of processed food, backed by traditional marketing strategies (heavy advertising on traditional media, coupons, brand extensions, etc.) are failing to hold on to their customers. The challenges can be found throughout the food value chain, from new competitors for grocery providers to new delivery mechanisms, from changes in generational food preferences with social media platforms to express their preferences to farmers who increasingly can and want to communicate directly with the end-users who actually eat the food that they produce. This access to more information opens more options (and opportunities) to buyers and suppliers all along the food value chain. Barely 100 years old, the grocery store model is becoming obsolete, and with it the organization of the food value chain must be re-written. So what does that mean for Big Food and the food supply chain? What directions can the industry take to adjust to the new competitive realities? This paper offers direction and guidance for Big Food and other producers in the food supply chain.
\end{abstract}

Keywords: Big Food, millenials, Amazon, Whole Foods, food supply chain JEL code: M00

\footnotetext{
${ }^{\oplus}$ Corresponding author: aconnolly@alltech.com
} 


\section{Introduction}

Amazon's purchase of Whole Foods ended any doubt that Big Food is in a battle for survival and that the grocery store is the battlefront. Worse for Big Food was the sharp drop in share prices of leading grocery providers when the deal was announced (Thomas, 2017), with the market leaders in the US, UK and France falling from 5-19\% in a single day (Shen, 2017), in effect a bet by the financial markets on who they think is winning the battle. It is an important story, but it is just the beginning: the changes facing food retailers will be rippling through the entire food value chain, profoundly affecting not just Big Food, but the entire chain.

\section{Food retailing}

There are a number of obvious synergies for Amazon with the purchase of Whole Foods, including: a start toward becoming one of the top five grocers by 2025 (Rosen, 2017); a tidy tie in with AmazonFresh (providing fresh foods through online ordering), and access to an affluent demographic that is already voting for healthy, clean label food with their food dollars. The purchase also reflects demographic changes: Amazon is how millennials are used to shopping. Most millenials have no memory of life before Amazon, and it is ubiquitous in their lives. The two-thirds who have attended any form of college or university (Ryan and Bauman, 2016) came of age with free Amazon Prime for ordering their textbooks. In major cities, they are already accustomed to delivery in two hours through Prime Now.

Yet Whole Foods has just $1.2 \%$ of the US grocery market, and Amazon just $0.2 \%$, and overall online food and beverage purchases account for just $2 \%$ of the total food and beverage market in the US (The Economist, 2017). Given the small scale, the response of the marketplace might seem overly dramatic, but it reflects an awareness by the financial markets that the purchase signifies deeper changes than just the venue or delivery mechanism for buying food products. As one analyst noted, 'I think this [deal] is certainly a game changer. Amazon's strategy will make retailers like Target and Wal-Mart ask themselves questions about where retail is headed.' (Thomas, 2017).

\section{The Big Food landscape}

Consumers are changing how they relate to grocery stores, increasingly circling the perimeter, focusing on produce and preferentially choosing fresh, local, and new, even unknown, brands while spending less time in the processed food aisles in the center. The next generation, the millenials, are increasingly shunning traditional outlets when buying food (Connolly, 2016a), and those who do wander the grocery aisles are making different choices. Traditional leading brands of processed food, backed by traditional marketing strategies (heavy advertising on television and media, coupons, brand extensions, etc.) are failing to hold on to their customers.

The food landscape is being torn apart, not by the food companies or government actions, but by consumers, led by prosumers (Connolly, 2016b; Havas, 2016). Since 2009, the lost market share of top U.S. food and beverage companies is equivalent to approximately $\$ 18$ billion (Kowitt, 2015). Years of fast growth and consolidation into segment-dominating behemoths has created companies that are too big to react nimbly to changes in the marketplace.

These super-sized companies were dubbed 'Big Food' in a nod to the market dominance of 'Big Pharma' that these companies aspired to. Instead they are feeling the heat of competition in a suddenly unfamiliar arena. Companies along the food value chain, from Archer Daniels Midland and Mondelez at one end, to CocaCola and Campbell Soup at the other, projected lower revenues and gross profits for 2016 (Higgins, 2017); sales in traditional supermarkets are projected to fall in parallel over the next several years (Ruddick, 2014).

The shift in consumer preferences is profound. The breakfast cereal aisle, for 100 years home to a key part of breakfast, was recently called the most dangerous in the grocery store by celebrity chef Michael Ruhlman 
(Strom, 2017). Sales of orange juice, another staple of a 'healthy breakfast', dropped $13 \%$ in just four years (Peterson, 2016) as consumers realized that in terms of sugar content, orange juice is not much healthier than soft drinks, a category whose sales have declined by nearly 20\% in six years (Sanger-Katz, 2015). Bottled water sales now surpass soft drinks (Allegri, 2017). The major soft drink manufacturers noticed this trend several years ago, and now own their own market-leading bottled water brands (e.g. Dasani by Coca-Cola and Aquafina by PepsiCo). Meanwhile, after decades of relatively slow growth, organic food sales more than tripled over the last decade (Kowitt, 2015). Even conservative, big box, price-conscious chains such as Aldi and Wal-Mart expanded their organic produce sections to meet demand: More than $80 \%$ of US households now buy some type of organic product (OTA, 2017).

The trend toward local, organic and less processed foods has become large enough to sustain new (or in some cases renewed) food pathways. From farmers markets to home-grown food production companies, consumers increasingly seek out both convenient and clean foods (i.e. not laden with unnatural ingredients and chemicals) (The Hartman Group, 2016). Both Whole Foods and Trader Joe's epitomize these efforts: healthy, fresh clean label food, an emphasis on own-label products, and simple meals packaged and ready to make. In the meantime, Blue Apron, Hello Fresh and their many competitors in the home delivery of ready-to-make meal kits are removing the need to even go to the market. The Amazon purchase of Whole Foods demonstrates this trend towards 'food as a delivery service... what is technically known as 'consumer convenience' and what is commonly observed as 'human sloth." (Thompson, 2017).

So, the boxed macaroni with powdered processed cheese (or ready to be microwaved) that many millenials grew up with is convenient; boxed macaroni and cheese made by a company started by a mom using all natural ingredients is just as convenient and 'healthier'; store-made ready to eat macaroni and cheese at the salad bar in the grocery store is even more convenient and seems even 'healthier' yet. Finally, 'home-made' from a kit delivered to your door is the most convenient and 'healthiest'.

\section{Transformative change}

The challenge to the food value chain is not simply new competitors for grocery providers, or new delivery mechanisms. Nor is it merely changing food preferences or a new generation with its own ideas and social media platforms for expressing them. It is also farmers who increasingly want, and have the ability, to communicate directly with the end-users who actually eat the food that they produce. It is not just high end, but mid-level restaurants sourcing their ingredients directly from specialty producers and restaurants serving 3-D printed food (Ahmed, 2017). It is the availability of information to participants throughout the value chain, whether marketers mining social media data instead of crude demographics or farmers choosing crops to plant based on production in other parts of the world. In short, it is an industry in the middle of transformative change.

Barely 100 years old (Ross, 2016), the grocery store model is becoming obsolete, and with it the organization of the food value chain gets re-written. Participants in the food value chain are now experiencing a period of rapid change rapid change and experimentation as the market finds a 'new normal'. McGahan (2004) describes industries in this situation as being on an 'intermediating trajectory', one in which businesses must protect the value of their assets while restructuring their trading relationships. The dramatic increase in information availability and contact between all parts of the chain (including the rise of the prosumers), and the rise in ways to get food from producers to end consumers, puts the food value chain firmly on the 'intermediating trajectory'.

The 'intermediating trajectory' is hard to recognize initially because only individual segments of the value chain are affected, while the period of rapid change makes it particularly difficult to navigate (McGahan, 2004). Companies must identify which of their core assets continue to have value, while preparing to drop segments as they become unprofitable, while continuously re-evaluating trading relationships with both customers and suppliers. The core assets of Big Food and the food value chain (brands, knowledge, 
production and distribution systems, etc.) still have value, but all the participants will need to adjust to the new environment.

During this period of change and transition to an as-yet unknown market structure, taking a 'reactive segmentation' (Phillips-Connolly, 2007) approach, at both operational and strategic levels, provides a framework for decision-making. Operationally, the key is to be prepared for volatility. Participants in the food chain need to assess their value chain modularly, to identify the relative profitability of each segment, and prepare to drop elements as they become unprofitable. Steps to take include:

- Pursue active, continuous information gathering, particularly on the changing nature of the competition, but also industry capacity, reduction of variance and forecasting errors.

- Review the value chain, tracking the relative profitability of core activities so that as soon as they are no longer profitable they can be outsourced or dropped.

- Manage existing relationships, being prepared to change or unwind them as the value chain segments and reconfigures, while staying particularly responsive to the interests of core customers.

- Improve efficiency and effectiveness through incremental process improvements (not through major investment) as long as business is profitable.

- Use supply chain management techniques such as reducing lead times, postponement and build to order, minimizing stock levels, and third-party logistics.

Cost cutting through substitution, 'shaving' (using less expensive ingredients or packaging) and rationalization are familiar and well-developed tools within Big Food, and it is already deploying all of these approaches in reaction to changes in the marketplace.

It can be difficult to recognize that even successful product areas may need to be jettisoned. Unilever recently decided that, despite owning the top two brands of margarine, the decline in the market for spreads (margarines, etc.) in developed markets is irreversible, and are no longer profitable enough to keep (Bray, 2017) and are selling that business unit.

\section{Strategies}

In most segments of the food chain the dominant strategy has been to develop deeper relationships with trading partners, but in this period of rapid change it is important to reassess the terms of each of these relationships. This can be particularly challenging for firms whose relative power in the relationship is low (for example, a supplier to Wal-Mart). Points to consider during this period of volatility include:

- Segment buyers by profitability and longer-term prospects.

- Identify trading partners (suppliers and buyers) long term interests, as a basis for develop risk-andbenefit sharing approaches and incentives to motivate trading partners and align interests.

- Use alliances with new entrants to the industry to access knowledge about the evolving market paradigm, but be aware that the new paradigm may be using the resources and/or credibility of the old as a springboard to help itself grow - hence the volatility of these relationships, which rarely last.

- Assume that alliances with both existing and new trading partners (including exclusivity, access to needed assets through partnering. joint ventures, mergers, acquisitions, etc.) will be limited in both scope and duration.

- Develop strong internal-communication systems to manage information flows and to identify when to decouple activities.

Big Food is responding to changing trends by adjusting recipes (for example, to reduce sugar or salt), being more 'natural', buying small 'healthy' food makers, and creating organic or natural own brands in an effort to stay ahead of the trend towards healthier food. For example, General Mills bought buying Annie's, a small line of organic pastas and snacks primarily targeted at children; and Kroger's successfully launched an own-label line of organic/healthy/natural food and non-food products ('Simple Truth'). Unilever's sale of its spreads business while simultaneously buying Sir Kensington's (a maker of specialty condiments) 
reflects a re-focusing of their food segment away from foods now seen as 'processed' and prosaic and toward specialty condiments and desserts. Sir Kensington's needed the market access that Unilever provides, and Unilever recognized that consumers are increasingly willing to try new, 'clean' label products and aimed to contain the 'threat' to legacy brands such as its market leading mayonnaise, Hellmann's (Kell, 2017).

In practice, though, most of these examples are simply doing more of the same. Unilever bought Ben \& Jerry's ice cream more than 15 years ago, saying that it represented a trend towards 'enjoyment of life' (Hays, 2000). The robust growth of the Aldi and Lidl 'hard' discount grocery chains can seem simply a more intense phase of normal competition, and their emphasis on carrying a limited product range of largely private label products, with very low prices (Choi, 2017) as extensions of the Sam's Club or Costco model.

On the 'Intermediating' trajectory, the linear understanding of the chain itself is under threat. General Mills, one of the giants of Big Food, has one of the best diagrams of the food chain. Direct communications between purple consumers and virtually all the other segments, growing direct communications and even direct trading relationships between orange purveyors and the blues and greens of early stage production are examples of the process of disintermediation engulfing the food value chain (Figure 1).

As the examples above indicate, food companies are adjusting to the changing marketplace. The question is: do they see this as simply a normal course correction, or do they recognize the scale, volume and velocity of change that is underway?

\section{Summary}

Transformative change can be hard to recognize, especially in the early stages. Big Food, along with many of the participants in the food value chain, might hope that building a social media presence and tweaking their offerings will be enough see them through the current changes. The fast growth of hard discounting grocery chains such as Lidl and Aldi may reassure other supermarkets that the role of supermarkets is still strong. But it is more likely that this is the swan song of the old order. Nobody knows how long the song will last, or what the new song will be, but as the market tumble from Amazon's purchase of Whole Foods indicates, there are players who are already warming up. Using the steps outlined here can help Big Food and other participants in the food chain prepare for the big changes that are coming.

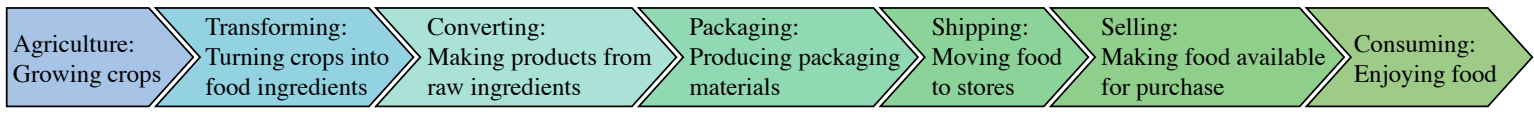

Figure 1. Food supply chain. Rendition of original image, courtesy of General Mills. 


\section{References}

Ahmed, R. 2017. 4 famous restaurants that use 3D printers. 3D Printing online, March 24. Available at: http://tinyurl.com/yc9dnz8s.

Allegri, C. 2017. Americans drank more bottled water than soda in 2016. Reuters online, March 9. Available at: http://tinyurl.com/yaqojd9a.

Bray, C. 2017. Unilever to sell its spreads business and restructure. New York Times online, April 6. Available at: http://tinyurl.com/yd5of23h.

Choi, C. 2017, Europe's Aldi and Lidl take on U.S. grocery giants with discount strategy. Seattle Times online, June 15. Available at: http://tinyurl.com/yaqbao2s.

Church, J. 2015. How General Mills is advancing a sustainable supply chain. General Mills. Available at: http://tinyurl.com/y8zo7wqs.

Connolly, A. 2016b. Living in the age of the prosumer. LinkedIn Pulse article published on September 30. Available at: http://tinyurl.com/y7o4pmhc.

Connolly, A. 2016a. The future of the supermarket: a daycare for the elderly? LinkedIn Pulse article published April 8. Available at: http://tinyurl.com/ya5g42mk.

Havas, 2016. Eaters digest: the future of food. Havas the Mag, July 26. Available at: http://tinyurl.com/ yauor4fy.

Hays, C. L. 2000. Ben \& Jerry's to Unilever, with attitude. New York Times, April 13. Available at: http:// tinyurl.com/2a75qwj.

Higgins, K.T. 2017. Poor sales and profits in 2016 for top food and beverage companies. Food Processing online, April 13. Available at: http://tinyurl.com/y9a67azj.

Kell, J. 2017. The maker of Hellmann's mayonnaise has bought a fancier upstart. Fortune online, April 20. Available at: http://tinyurl.com/yaagncfp.

Kowitt, B. 2015. Special report: the war on big food. Fortune online, May 21. Available at: http://tinyurl. com/nkzt72r.

McGahan, A.M. 2004. How industries change. Harvard Business Review online, October issue. Available at: http://tinyurl.com/yadpdl81.

OTA. 2017. Organic, big results available at small seeds. Organic Trade Association Infographic. Available at: http://tinyurl.com/y8xyvj4g.

Peterson, H. 2016. orange juice is being called a massive scam - and now it's disappearing at breakfast in America. Business Insider, October 13. Available at: http://tinyurl.com/y7hzhogc.

Phillips-Connolly, K. 2007. A typology for strategic supply-chain management: bridging the gap between operations and strategy. Thesis from Trinity's Access to Research Archive. Available at: http:/tinyurl. com/y8gz8fsz.

Rosen, E. 2017. Why Amazon bought whole foods. L2: Daily Insights, June 19. Available at: http://tinyurl. com/ya33jfdg.

Ross, A. 2016. The surprising way a supermarket changed the world. Time Online, September 9. Available at: http://tinyurl.com/ybe4a6p9.

Ruddick, G. 2014. Superstores could have just five more years on top. Telegraph online, June 29. Available at: http://tinyurl.com/ybv6addr.

Ryan, C.L. and K. Bauman. 2016. Educational attainment in the United States: 2015. Available at: http:// tinyurl.com/15r62f3.

Sanger-Katz, M. 2015. The decline of 'big soda'. New York Times online, October 2. Available at: http:// tinyurl.com/mabpu94.

Shen, L. 2017. Amazon's $\$ 13.7$ billion whole foods deal just made grocery stocks plunge. Fortune online, June 16. Available at: http://tinyurl.com/ybhn42nv.

Strom, S. 2017. What's new in the supermarket? A lot, and not all of it good. New York Times online, May 16. Available at: http://tinyurl.com/ya7m3uu9.

The Economist. 2017. An industry shudders as Amazon buys Whole Foods for \$13.7bn. The Economist June 16. Available at: http://tinyurl.com/yb85ogp6. 
The Hartman Group. 2016. Is a reckoning at hand for big food companies? Forbes online, August 17. Available at: http://tinyurl.com/y7szxt2r.

Thomas, L. 2017. Target, Wal-Mart endure the aftermath of Amazon's Whole Foods buy; stocks still falling. Available at: http://tinyurl.com/y9eslbp3.

Thompson, D. 2017. Why Amazon bought whole foods: the retailer's $\$ 14$ billion bet isn't just about the future of food. It's about the future of commerce - especially for rich urban consumers. The Atlantic online, Jun 16. Available at: http://tinyurl.com/y8r8cybs. 
